\title{
Effective Clinical Project Management to Streamline Clinical Trial
}

\author{
Madhuri Patel* \\ Texila American University, South America
}

Submission: June 01, 2018; Published: September 06, 2018

*Corresponding author: Madhuri Patel, Texila American University, Guyana, South America, Tel: 9558196458;

Email: madhuri.patel1988@gmail.com

\begin{abstract}
There is serious amount of time and efforts involved in clinical research industry supporting the drug development process with the project management tool. The question arise is, is clinical trial project? Clinical trial has defined beginning and end, no matter whether it will continue for several months to 10-15 years. The finance and human resources for conducting those trials are finite It is quite healthy to handle clinical trial as a project which makes management well defined and structured. The deliverable of every clinical trials is unique, but it can be defined as result. clinical trial is always characterized by its progressive elaboration and a well-prepared clinical trial protocol (CTP) is an example of a step of development. Managing clinical trial required efficient trial management, whatever the size and complexity it is. For the past three decades, industry has invented and reinvented the trial management wheel. To improve the successful and timely delivery, it is time to produce standard trial management guidelines.
\end{abstract}

Keywords: Clinical trial; Project management; Clinical trial management; Project manager

\section{Introduction}

Over many decades, Eminent researchers have identified the need of large, randomized controlled trial in order to provide highest level of evident for guiding clinical practice. However, very few articles and materials have been published on how to manage these huge important trials. The lack of structured, practical and businesslike approach to trial management can be one of the reasons for failure of trial. The project management is a vital tool for conducting any clinical trials starting from planning stage. The duration of time spent for trial initiation and planning are quite short. However, improper initiation and bad planning can impact the outcome of trial especially in terms of extended duration of next phases and low profit rate. It is clarified that clinical trials need to establish and implement project management systems, irrespective of the complexity, cost, size and duration [1].

It is crucial that every effort to be made to ensure that the trial is implemented simply and managed efficiently as it involved huge human and financial resources and time which warrants expert management and needs to be managed from its inception like any other business. Also, it is very important and mandatory to deliver high-quality trials. It is now well recognized that the well-designed trials are important to address clinical questions, but science alone will not be sufficient to deliver high quality trials successfully. The key challenge is to establish and implement management systems and techniques that are effective and responsive to the needs of the trial and the trialist [2].

The step collaboration emphasis on that anyone involved in clinical trial should understand the needs at various stages of trial and put greater efforts on Conduct (the process of actually doing trials) [3]. An analysis of 114 Multicentre trials funded by the National Institute of Health Research (NIHR) Health Technology Assessment (HTA) and UK Medical Research Council (MRC), STEPS [3] showed that $45 \%$ failed to reach $80 \%$ of the prespecified sample size. Less than one third of the trials recruited their original target number of participants within the time originally specified, and around one third had to be extended in time and resources. In addition, the MRC acknowledged that the failure of some trials can be due to practical problems with trial management rather than scientific problems or problems with the trial design [4].

\section{Why "Management" is the Key?}

Clinical research are instances of project which take systematic efforts to answer scientific and health related questions/problems. Hence, the same project management methods and principles can be applied to clinical research trials [5]. Prescott et al. have classified factors limiting the quality and 
progress of randomized trials [6]. They have reported barriers to investigator participation that included time constraints, patient-doctor relationships, concerns for patients, lack of reward and recognition. They have listed certain barrier to patient participation includes concern for uncertainty and consent, additional demands and requirements to participate in trail (Patient responsibilities). They have suggested that to overcome these barriers, trials protocol and data collection should be as straightforward as possible, which will demand less efforts form the participating patients and investigators. The recruitment process should be planned carefully and piloted regardless of complexity of trial. On the basis of experience in noncommercial academic initiated trials, Farrell and Kenyon [7] in The Guide to Efficient Trial Management suggest that actively managing every aspect of the trial is key to success.

\section{Role of Project Manager in Clinical Trial}

Missing effective leadership at project level is one of the major obstacles in clinical trials. Clinical trials have become complex and multifunctional given intense competition for well recruiting sites, cost and time, complex regulations in different countries and large multination stakeholder team. With these reasons, project managers are expected to take ownership of a project starting from beginning and provide leadership through develop process and deliver result on time and budget. The project manager is less about directing operational work and more about managing remotely and understanding global needs and implementation of innovative technologies. The role is balance of science and business. Also, the soft skills the team dynamic components and the relationship pieces, which are critical for the successful project manager.

The importance of trial/project manager is recognized by the industry and regulatory bodies such as NIHR HTA Program, and they recommend that all trials appoint a dedicated project/ trial manager. Preferably, trial managers should be involved early in the trial design phase and funding application as they can make valuable contribution which eventually helps saving money and avoid unworkable systems, but this is rarely possible because of funding constraints.

The body of knowledge available to guide trial managers is very limited, despite the complex role and responsibilities. Despite the complex responsibilities of this role, the body of knowledge available to guide trial managers is very limited. In 1998, Farrell [8] described the need for trial management models and methodology to be established, yet more than 10 years on very little recognized reference material, other than The Guide to Efficient Trial Management [7] is readily available. It is also important to establish well-trained project management team which can be deciding factor in the success or failure of trial. However, the team cab be built depending on the complexity and needs of individual trial. The role of project management in general is less mature in clinical trials than other industries, but this is changing rapidly, and increasingly maturity is putting emphasis on organization, planning and control.

\section{Importance of Project planning}

Some believes that the project plan is just list of activities and deliverables, timelines and milestones. Clinical trial has the same features as other business projects as defined in the field of project management [9]. This feature includes a clear objective, required a team, a set timeline, defined resources, task lists etc. The project management body of knowledge (PNBOK) guide had listed five processes as initiations, planning, executing, controlling and monitoring and closing across the project life cycle [10]. Clinical trials also consist a series of process, a set of action as other business projects have. The five basis processes are Initiation (defining and formulating clear objectives), planning (organizing a team with the requisite knowledge and skills; setting a timeline and an appropriate methodology; defining resources to achieve the project objectives; planning for risk management), executing (conducting the project), monitoring and controlling (operating a quality control system, and finally monitoring progress in accordance with the project program), and analysis and reporting. These five stages are the life cycle of any clinical trial. Hence preparing management plan is the key for any successful clinical trial. The management plan should include the role and responsibilities for essential activities such communication with different parties involved, as staff recruitment, monitoring plan, risk management, safety reporting, data management, analysis, report writing, and how resources will be used.

The project management also required analyzing data to make decisions and adjustments. The clinical research industry does It well- we look at data regulatory to make large decisions or changes, such as whether to continue, adjust or terminate the trial. For example, the trial has developed unexpected recruitment risk. How do we adjust quickly, applying data to minimize delays? This information allows us to quickly determine what changes are required to recruitment strategies, putting the project timelines back on track. Another discipline is managing risk. This required clear understating of project, what stockholders trying to accomplish, and every participants' role and responsibilities.

\section{Key Areas for Today's Project Manager}

The evaluation in clinical research industry has shifted the expectations between client and Contract Research Organization, particularly on project manager. Same time clinical trials have become significantly complex due to many reasons. All this these trends have a major impact on the role pf project manager role. Project managers usually have been professed as process administrator while managing team and will be direct contact with client. What the clinical research industry has observed and adapting to is the need for managers to provide strategic leadership, understanding bigger picture of 
overall plan, and be like a "CEO" of the project to get successful outcome. Project managers need to invest in a more formal and proactive risk management strategy. There needs to be a mind shift from purely focusing on operational risks to a more holistic view including characterizing critical data, identifying any risks impacting subject safety and data integrity to support a total quality approach throughout the project begging to end.

Project data is available at our fingertips with the implementation of sophisticated predictive analytic tools. There has been an increased demand on a project manager to demonstrate proficiency on analytical skills to identify possible risks and opportunities during life on project. The project management team cannot work with what once were considered gold standard. Project manages need to be agile to Be creative and proactive, always strive for better solutions and adopt innovations that present themselves and Adjust based on future needs. PMs should be up to date with market trends to effectively manage business value to be true influencers and establish successful relationships with clients and internal team. They will drive decisions and understand how to take calculated risks to maximize opportunities for stakeholders. Due to the new challenges project managers are facing, CRO business leaders need to emphasize three key areas: people, systems and processes. Such as,

i. Investments in employee engagement, including increased opportunity for development and strengthened connections, are essential.

ii. Establishing effective support functions and leadingedge technologies.

iii. Focus on lean processes, agile learning opportunities and adequate just-in-time training.

There are other qualities of clinical project manager which make them successful in their role.

i. Knowledgeable: One of the most important quality is to have knowledge and experience with different functional areas. They should have overall knowledge of how tasks are performed within each function.

ii. Organized: During the project life cycle, there will be many moving parts and goals are never done sequentially but simultaneously. The project manager should be able to vigilant about everything going on all the time.

iii. Trusting: They should trust their team to get tasks done without micromanagement. Also, they must build the trust and should be able to assist team if required.

iv. Approachable: Project manager should be collaborative, helping and must set realistic expectation from the team members. It is always a great practice to set a tone that everyone in team is on same page, with same goals, rather than just delegating tasks. v. Transparent: The project manager should be transparent with the team. It is always great if project manager openly discusses challenges and willing to take others' suggestions, able to acknowledge when they need help.

Project managers are the bridge between the strategists, business leaders and stakeholders, so leadership skills are required to articulate strategy. The leadership role also includes to motivate and influence team members. Clinical trial projects are often long, difficult and complex; and problems like recruitment issues, timelines delays, unexpected withdrawals can be demoralizing. The project manager should be able to motivate team and sites to push through these difficulties, change planes as needed, and execute their tasks.

\section{Conclusion}

A good project plan greatly increases the probability of a successful project. Organizations that fail to include the right people early in the planning process will encounter unanticipated problems during the project. It would be great if trialists, funders, trial managers and all interested groups come together to discuss and debate management methods, which eventually will give guidelines for running and managing clinical trials successfully. Also, editors of medical journals should consider the importance of how clinical trial is actually carried out and require that trial management methods be part of articles considered for publication. If trial management continues to be unrecognized through, it will be to the disadvantage of future research and health care.

\section{References}

1. Farrell B, Kenyon S, Shakur H (2010) Managing clinical trials. Trials 11:78.

2. Francis D, Roberts I, Elbourne DR, Shakur H, Knight RC, et al. (2007) Marketing and clinical trials: a case study. Trials 8: 37.

3. Campbell MK, Snowdon C, Francis D, Elbourne D, McDonald AM, et al. (2007) Recruitment to randomised trials: strategies for trial enrolment and participation study. The STEPS study. Health Technol Assess 11(48): iii.

4. Warlow C (2003) Clinical trials for tomorrow funded by the MRC: Future policy report raises several unanswered questions. BMJ 327(7409): 240-241.

5. Hastings CE, Fisher CA, McCabe MA, Allison J, Brassil D, et al. (2012) Clinical research nursing: a critical resource in the national research enterprise. Nurs Outlook 60(3): 149-156.

6. Prescott RJ, Counsell CE, Gillespie WJ, Grant AM, Russell IT, et al. Factors that limit the quality, number and progress of randomised controlled trials. Health Technol Assess 3(20): 1-143.

7. Farrell B, Kenyon S (2014) A Guide to Efficient Trial Management. ( $4^{\text {th }}$ edn), National Institute for Health Science, UK.

8. Farrell B (1998) Efficient management of randomised controlled trials: nature or nurture. BMJ 317(7167): 1236-1239.

9. (2000) A Guide to the Project Management Body of Knowledge (PMBOK Guide). Project Management Institute, US, pp. 596. 
10. Payne JM, France KE, Henley N, D'Antoine HA, Bartu AE, et al. (2011) Researchers' experience with project management in health and

This work is licensed under Creative Commons Attribution 4.0 License DOI: 10.19080/CTBEB.2018.16.555937 medical research: results from a post-project review. BMC Public Health 11: 424

Your next submission with Juniper Publishers will reach you the below assets

- Quality Editorial service

- Swift Peer Review

- Reprints availability

- E-prints Service

- Manuscript Podcast for convenient understanding

- Global attainment for your research

- Manuscript accessibility in different formats ( Pdf, E-pub, Full Text, Audio)

- Unceasing customer service

Track the below URL for one-step submission https://juniperpublishers.com/online-submission.php 